\title{
The Effectiveness of Community-based Social Distancing for Mitigating the Spread of the COVID-19 Pandemic in Turkey
}

\author{
Hasan Durmuş ${ }^{1}$, Mehmet Enes Gökler², Selma Metintaş ${ }^{3}$ \\ ${ }^{1}$ Dörtyol District Health Directorate, Hatay, Turkey; ${ }^{2}$ Department of Public Health, Ankara Yildirim Beyazit University, Ankara, Turkey; ${ }^{3}$ Department \\ of Public Health, Eskisehir Osmangazi University/Faculty of Medicine, Eskişehir, Turkey
}

Objectives: The objective of this study was to demonstrate the effects of community-based social distancing interventions after the first coronavirus disease 2019 (COVID-19) case in Turkey on the course of the pandemic and to determine the number of prevented cases.

Methods: In this ecological study, the interventions implemented in response to the first COVID-19 cases in Turkey were evaluated and the effect of the interventions was demonstrated by calculating the effective reproduction number $\left(R_{t}\right)$ of severe acute respiratory syndrome coro navirus 2 (SARS-CoV-2) when people complied with community-based social distancing rules.

Results: Google mobility scores decreased by an average of $36.33 \pm 22.41$ points (range, 2.60 to 84.80 ) and a median of 43.80 points (interquartile range [IQR], 24.90 to 50.25). The interventions caused the calculated $R_{t}$ to decrease to 1.88 (95\% confidence interval, 1.87 to 1.89 ). The median growth rate was $19.90 \%$ (IQR, 10.90 to 53.90 ). A positive correlation was found between Google mobility data and $R_{t}(r=0.783 ; p<0.001)$. The expected number of cases if the growth rate had not changed was predicted according to Google mobility categories, and it was estimated to be 1381922 in total. Thus, community-based interventions were estimated to have prevented 1299593 people from being infected.

Conclusions: Community-based social distancing interventions significantly decreased the $R_{t}$ of COVID-19 by reducing human mobility, and thereby prevented many people from becoming infected. Another important result of this study is that it shows health policymakers that data on human mobility in the community obtained via mobile phones can be a guide for measures to be taken.

Key words: COVID-19, SARS-CoV-2, Social distance, Pandemics, Infectious disease

\section{INTRODUCTION}

Analyses of pneumonia cases that occurred in the city of Wuhan, China in December 2019 revealed the existence of a novel type of coronavirus that causes illness in humans [1].

Received: August 4, 2020 Accepted: October 23, 2020

Corresponding author: Hasan Durmus, MD

Dörtyol District Health Directorate, Hatay 31600, Turkey

E-mail: drhasandurmus@gmail.com

This is an Open Access article distributed under the terms of the Creative Commons Attribution Non-Commercial License (https://creativecommons.org/licenses/by$\mathrm{nc} / 4.0 /$ ) which permits unrestricted non-commercial use, distribution, and reproduction in any medium, provided the original work is properly cited.
Genetic studies conducted during the regional spread of the virus, which was initially named the 2019 novel coronavirus disease (2019-nCoV) by the World Health Organization (WHO) before it was renamed as severe acute respiratory syndrome coronavirus 2 (SARS-CoV-2), revealed that it has a $70-79 \%$ genetic similarity to the severe acute respiratory syndrome coronavirus (SARS-CoV) that caused a serious outbreak in 2003 $[2,3]$. In a short period of time, Thailand and Japan, the regional neighbors of China, became the first other countries where the disease was seen [4]. It eventually became clear that SARSCoV-2 is more infectious than SARS-CoV and the Middle East respiratory syndrome coronavirus (MERS-CoV), but has a lower fatality rate (3\%) than those observed for SARS-CoV and MERS- 
CoV (10 and 37\%, respectively), although the case fatality rate has varied across countries [5]. Although studies on the source of the disease found that SARS-CoV- 2 is $96.2 \%$ similar to coronaviruses found in bats, supporting the hypothesis that its original source was bats, it is not possible to speak clearly about the source of the disease since the Wuhan seafood market does not sell bats or bat meat [6,7].

This novel type of coronavirus with human-to-human transmission has spread rapidly all over the world, and the WHO declared coronavirus disease 2019 (COVID-19), the disease caused by SARS-CoV-2, a global pandemic on March 11, 2020 $[8,9]$. Many countries have set the primary goal of reducing the burden on the healthcare system by slowing down the epidemic through public health interventions such as social isolation, but few countries have accomplished this goal successfully $[10,11]$. After the first case of COVID-19 in Turkey was confirmed on March 11,2020, it became one of the countries where the epidemic spread most quickly in the world. As a result, a series of rapid and effective measures were taken, such as flight bans, closure of schools, postponements of sporting events, curfew for those under 20 years and over 65 years of age, and inter-provincial travel restrictions [12-14].

The basic reproduction number $\left(R_{0}\right)$, which is one of the fundamental tools used for evaluating epidemics and the spread of infectious diseases, simply shows the potential of the disease to spread in the community [15]. Likewise, the growth rate (GR) shows the change in the number of new cases per person over time in the course of an outbreak and is proportional to $R_{0}$ [16]. It is possible to evaluate the effect of social isolation and prevention measures in the COVID-19 pandemic by calculating $R_{0}$ and the GR, which are used to evaluate interventions and measures taken during the pandemic period $[11,17]$. Quantifying mobility using smartphones and global positioning system is an opportunity brought by the digital world that helps to show the effects of interventions implemented during the pandemic period [18].

The aim of this study was to demonstrate the effect of community-based social distancing interventions after the first case of COVID-19 in Turkey on the course of the pandemic and to determine the number of prevented cases.

\section{METHODS}

In this ecological study, the interventions implemented in response to the appearance of the first COVID-19 cases in Tur- key were evaluated and the effect of these interventions on the course of the pandemic was demonstrated by calculating the effective reproduction number $\left(R_{t}\right)$ of SARS-CoV-2 during periods when people complied with the community-based social distancing rules. According to Google mobility reports, the epidemic period was separated into 3 periods, with $25 \%$, $50 \%$ and $75 \%$ reductions in mobility, respectively, based on the effects of social distancing interventions [18]. The level of mobility was determined by the daily data reaching the corresponding threshold at least twice within the specified period.

Google mobility datasets show how visits and the length of stays at various places change compared to baseline. Google calculates these changes using the same kind of aggregated and anonymized data used to show popular times for places in Google Maps. Changes for each day of the week were compared to a baseline value, which was defined as the median value for that day of the week during the 5 -week period from January 3, 2020 to February 6, 2020 [18].

The smartphone usage rate in Turkey is $89 \%$ among those aged 16-64 years old and $84 \%$ of mobile-based web traffic accounted for Android devices in January 2020 [19]. Therefore, it is reasonable to interpret a decrease in smartphone mobility as a proxy indicator of a decrease in interactions throughout society. The daily number of new cases was taken from the website that was created by the Ministry of Health of Turkey to show the current guidelines for the COVID-19 pandemic and the daily number of cases [20].

The GR shows the rate of increase in the number of active cases, which is calculated by subtracting the total number of deaths and cumulative recovered cases from the cumulative number of total cases. Deaths refer to those who died due to COVID-19, and recovered cases were defined as those who were treated with COVID-19 and discharged from the hospital. A constant decrease in the GR over time indicates that the epidemic is progressing in a controlled manner. The GR is calculated using the following formula: $G R_{t}=\left(A_{t}-A_{t-1}\right) / A_{t-1}$, where $A$ is the number of active cases, as defined above, and $t$ indicates a given day [21].

The projected number of cases in the study was calculated according to the average GR seen during the periods of reduction in mobility, which was calculated using data from Google. It was predicted how many cases would have be seen if the GR in the previous period had continued. 


\section{Statistical Analysis}

The data obtained were evaluated using SPSS version 22.0 (IBM Corp., Armonk, NY, USA). For descriptive statistics, the number, percentage, mean \pm standard deviation (range), and median (interquartile range, IQR) were used. The correlation between Google mobility data and $R_{t}$ was tested by Spearman correlation analysis. As the data were not normally distributed, the Spearman rank correlation test was utilized to examine correlations between variables. $\mathrm{R}$ version 3.6.3 (https://cran.rproject.org/bin/windows/base/old/3.6.3/) was used to calculate $R_{t}$. In the statistical analysis, the exponential-growth $R_{t}$ calculation method by Obadia et al. [22] was used when comparing paired time points while, while the calculation method reported by Cori et al. [23] was used for weekly $R_{t}$ calculations from the last day backward. $R_{t}$ values were calculated as the daily value corresponding to the 5 -day moving average after the first 100 cases, using a serial interval value of 7.5 days and a standard deviation of 3.4 days [24]. The 5-day moving average was used to minimize effects such as changes in the number of tests, laboratory problems, and differences in the timing of new case reports. The level of statistical significance was set at $p$-value $<0.05$.

\section{Ethics Statement}

During pandemic period, ethical committees closed. However, this research approved by Turkish Ministry of Health (No. 2020-05-05T13_55_20).

\section{RESULTS}

Between March 11, 2020 and April 18, 2020, 82329 cases were diagnosed, 1890 people died, and 10453 patients recovered. In the same period, the Google mobility score decreased by an average of $36.33 \pm 22.41$ points (range, 2.60 to 84.80 ) and

Table 1. Distribution of the number of cases, deaths, recovered patients, Google mobility scores, growth rate (GR), and effective reproduction number $\left(R_{t}\right)$

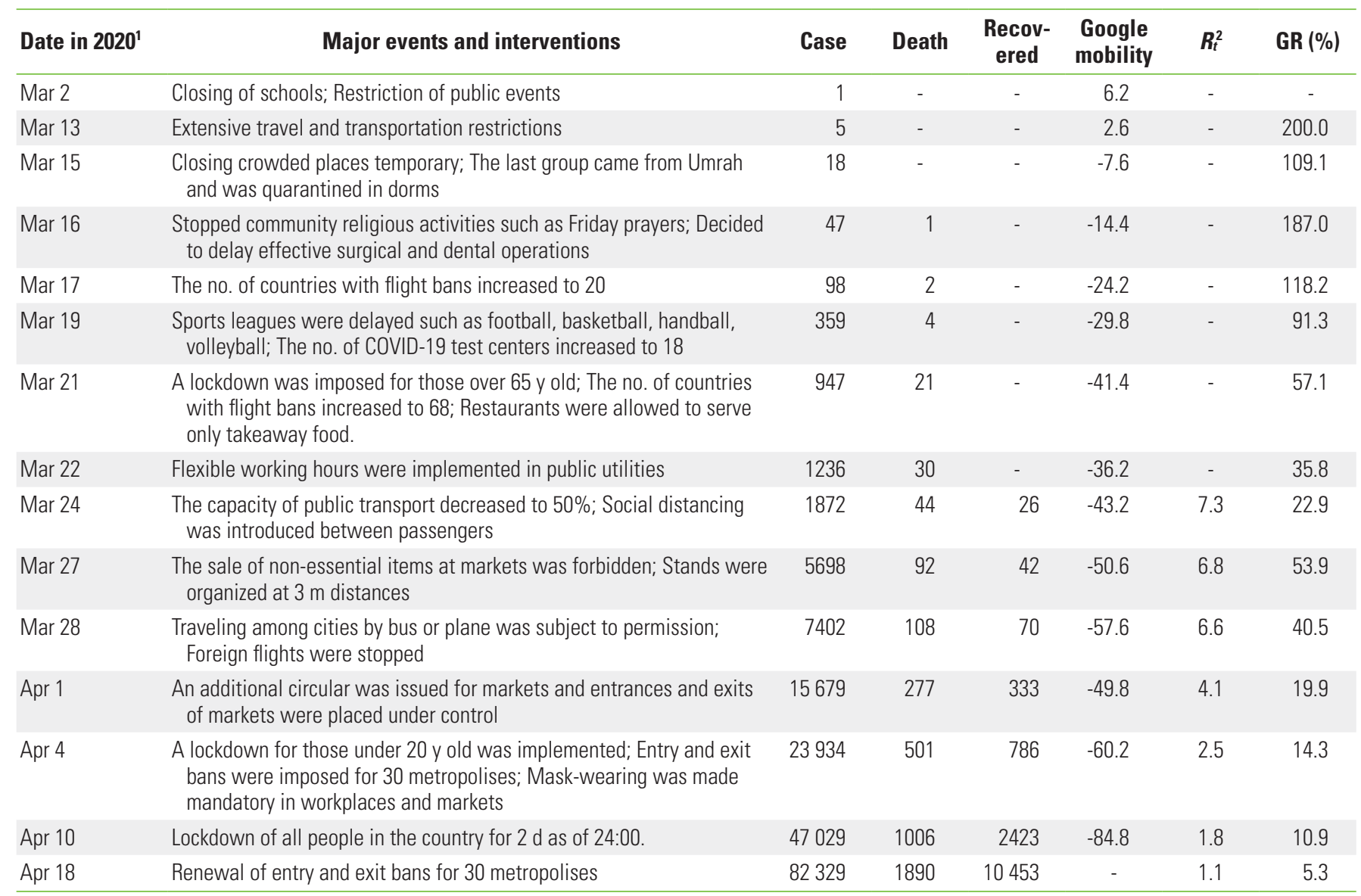

${ }^{1}$ Aaccording to major events and interventions during the coronavirus disease 2019 (COVID-19) pandemic period in Turkey.

${ }^{2} R_{t}$ was calculated using the method of Cori et al. [23]. 
a median of 43.80 points (IQR, 24.90 to 50.25) (Figure 1). Including interventions, the calculated $R_{t}$ value was 1.88 (1.87 to 1.89). The median GR was $19.90 \%$ (IQR, 10.90 to 53.90 ). A positive correlation was found between Google mobility scores and $R_{\mathrm{t}}$ values $(r=0.783 ; p<0.001)$ (Figure 2). Table 1 presents data on the number of cases, deaths, and recovered patients, the Google mobility data, and the distribution of $R_{\mathrm{t}}$ and $\mathrm{GR}$ values in Turkey during the COVID-19 pandemic period when active interventions were implemented.

$R_{t}$ values were calculated according to categories of decreas-
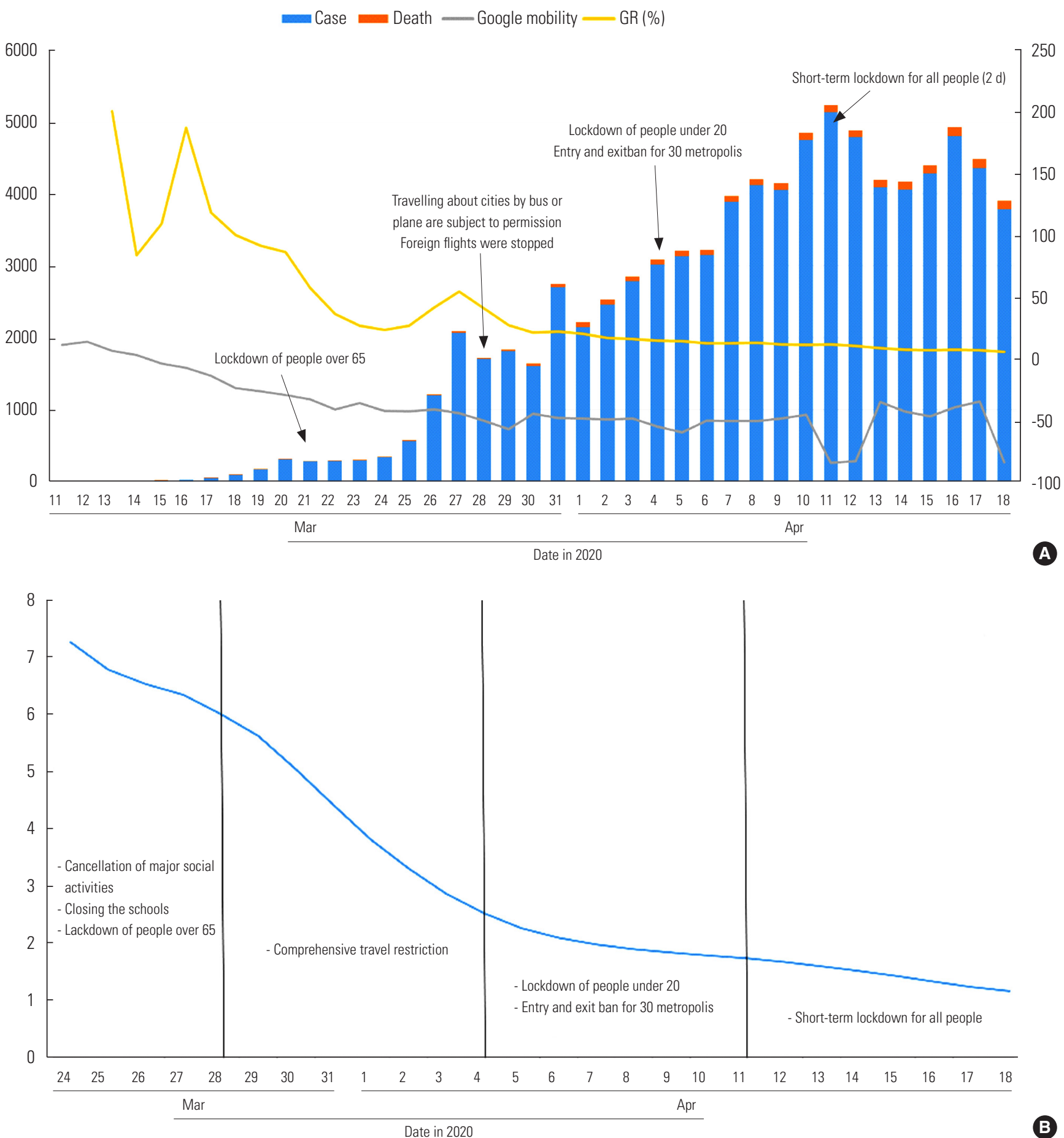

Figure 1. (A) Distribution of the number of cases, deaths, Google mobility data, and growth rate, (B) effective reproduction number values over time. 
es in the Google mobility data. A $25-50 \%$ decrease in mobility caused the $R_{t}$ value to decrease to 7.86 , a $50-75 \%$ decrease to caused it to decrease to 1.82 and a $>75 \%$ decrease caused the $R_{t}$ to decrease to 0.88 . If the GR had not changed, the expected number of cases was predicted according to Google mobility categories, and it was estimated to be 1381922 in total. Therefore, reduced mobility due to community-based interventions prevented 1299593 people from being infected.

The number of cases and deaths, Google mobility scores, and GR are shown in Figure 1, along with $R_{t}$ during the pandemic period with major interventions.

\section{DISCUSSION}

The most important step in the fight against infectious diseases is to break the chain of infection, and the methods used to achieve this are to prevent transmission, to develop immunity in susceptible individuals, and to destroy the infectious agent [25]. In this context, personal hygiene, food hygiene,

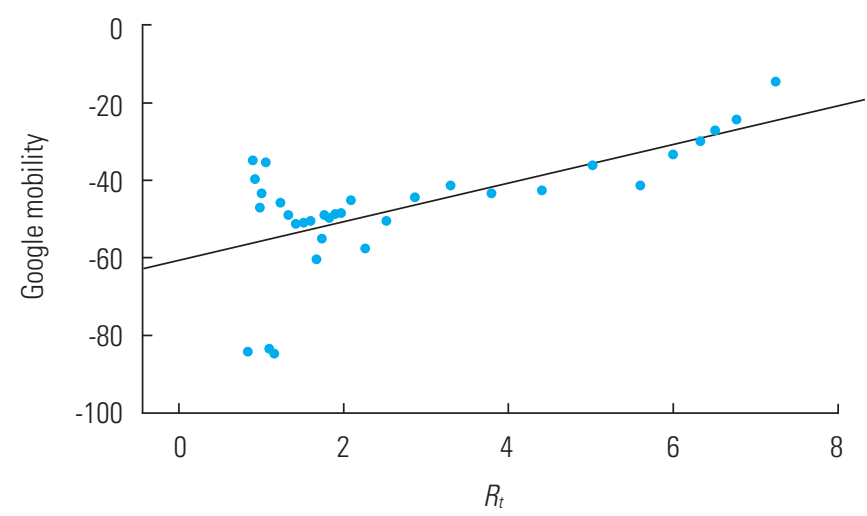

Figure 2. Correlation between Google mobility data and effective reproduction number $\left(R_{t}\right)$ values. vaccination, isolation of sick individuals, and appropriate medical management of sick individuals are known to be effective methods for infections transmitted by droplets $[25,26]$. The COVID-19 pandemic, which started in China, spread to affect the entire world in a short period of time, as its $R_{t}$ was higher than those of SARS and MERS, which caused previous pandemics, and influenza $[27,28]$. The finding that SARS-CoV-2 can be transmitted by asymptomatic individuals brought social isolation to the forefront, and plans have been made to minimize contact among individuals by isolating and quarantining people at home and restricting the use of public areas [29,30]. Community-based isolation measures provide time for arrangements and improvements to be made in the health system in the course of the pandemic. In addition to the rapid progression of COVID-19, the fact that it has a particularly aggressive clinical course in individuals with advanced age and chronic diseases has led to a rapid increase in utilization of intensive care units and hospital beds; the resultant pressure on hospitals' capacities has heightened the importance of measures to extend the epidemic over time (sometimes referred to as "flattening the curve") as part of the fight against COVID-19 [11,31]. According to Ryu et al. [32], non-pharmaceutical measures were reported to reduce transmissibility by a maximum of $33 \%$ without resorting to a strict lockdown strategy. In order to control the epidemic, curfew restrictions are required when contagiousness is increasing and the epidemic is out of control. In addition, studies have shown that loosening social distance measures is the largest factor that contributes to the spread of COVID-19 becoming out of control. Religious activities and social activities of individuals in the same age group have been found to be a common cause of outbreaks [33]. Social isolation measures are especially important in countries such as Korea and Turkey, where social gatherings are fre-

Table 2. Estimated effective reproduction number $\left(R_{t}\right)$ and growth rate (GR) according to decreases in Google mobility data

\begin{tabular}{lccccc}
\hline \multirow{2}{*}{$\begin{array}{l}\text { Google mobility decrease } \\
\text { (dates in 2020) }\end{array}$} & \multicolumn{5}{c}{ GR (\%) } \\
\cline { 2 - 6 } & $\begin{array}{c}<\mathbf{2 5} \\
\text { (Mar 11-Mar 19) }\end{array}$ & $\begin{array}{c}\text { 25-50 } \\
\text { (Mar 20-Mar 28) }\end{array}$ & $\begin{array}{c}\mathbf{5 0 - 7 5} \\
\text { (Mar 29-Apr 11) }\end{array}$ & $\begin{array}{c}\text { > 75 } \\
\text { (Apr 12-Apr 18) }\end{array}$ & $\begin{array}{c}\text { Total } \\
\text { (Apr 11-Apr 18) }\end{array}$ \\
\hline$R_{t}(95 \%$ CI) & - & $7.86(7.40,8.34)$ & $1.82(1.78,1.84)$ & $0.88(0.84,0.93)$ & $1.88(1.87,1.89)$ \\
Mean (\%) & $126.98(83.54,170.43)$ & $43.35(28.03,58.67)$ & $15.65(12.85,18.44)$ & $7.15(5.77,8.54)$ & $39.95(24.34,55.56)$ \\
Total cases & 359 & 7043 & 44765 & 30162 & 82329 \\
Expected case no. if GR had not changed & 42043 & 316457 & 75379 & 272043 & 1381922 \\
Prevented case no. based on decreasing GR & 41684 & 309414 & 706614 & 241881 & 1299593 \\
\hline
\end{tabular}

$\mathrm{Cl}$, confidence interval.

${ }^{1}$ Predicted number of expected and prevented cases due to change in GR.

${ }^{2} R_{t}$ was calculated using the method of Obadia et al. [22]. 
quent.

With the quarantine of Wuhan in China and travel restrictions, sick individuals have been prevented from traveling to remote areas, with a major effect on preventing the spread of the disease [34]. As in the influenza pandemic, closure of schools in the COVID-19 pandemic is an early intervention that has effectively reduced the transmission of infection [35,36]. However, it is estimated that such measures may reduce the availability of health personnel if healthcare professionals are required to stay at home to provide child care, potentially increasing the mortality risk of COVID-19 patients [35,37]. Travel restrictions and cessation of flights were among the first measures taken by Turkey, and accordingly, as a result of these interventions based on quick decision-making, human mobility rapidly declined (Figure 1). As mobility decreased by $50-75 \%$, the $R_{t}$ value decreased from 7.52 to 1.82 , with measures taken for crowded places, such as inter-provincial travel centers, markets and marketplaces, as well as a curfew for individuals under the age of 20. Although the initial $R_{t}$ value for Turkey appeared to be 7.52 based on calculations using the daily number of cases, the reason for this high value is thought to be the addition of new cases detected during screening since Turkey brought thousands of citizens from abroad and quarantined them, as well as the multicenter emergence of the pandemic [14]. Moreover, European countries such as Italy, France, Germany, and Spain reached their first 100 cases within 23-36 days, while Turkey reached this number in only 7 days. $R_{t}$ decreased very rapidly after the first 10 days due to the isolation of citizens returning from abroad. Further analyses of this rapid increase in cases in Turkey with prospective studies and research into the causes for this increase will contribute to the explanation of the pandemic period. The reason for the difference in $R_{t}$ values between Figure 1 and Table 2 that different methods were used. Table 2 shows time periods of decreasing Google mobility scores, so we used the method of Obadia et al. [22] to describe the $R_{t}$ values during these time periods. Figure 1 shows continuous $R_{t}$ values, so the method developed by Cori et al. [23] was used.

The major limitations of this study are that the evaluation of the course of the COVID-19 pandemic in Turkey was conducted using daily data presented by the Ministry of Health, and the number of positive cases among citizens coming from abroad, as well as whether the pandemic emerged from a single center or multiple centers independently of each other, could not be evaluated due to a lack of information.
A major limitation caused by the study design is that it presents correlations of the decline in $R_{\mathrm{t}}$ with a single factor. However, although community-based interventions in Turkey were important, the role of ease of access to the healthcare system, COVID-19 management teams, and effective use of personnel at every stage of the healthcare system, including primary and secondary care, in pandemic control cannot be ignored [14]. Increasing the test capacity in Turkey to identify sick individuals as part of pandemic control, and rigorously detecting and isolating contacts may have also been effective contributors to the decrease in $R_{t}$.

The societal adoption of the use of face masks and more regular hand hygiene will also reduce the spread of COVID-19 $[38,39]$. However, during the period of this study, Turkey enforced the use of masks in only a few limited areas, such as indoor areas and supermarkets [14]. The sharp decrease in mobility and high adaptation to social distancing reduced the impact of factors such as masks and hand hygiene on $R_{t}$.

In conclusion, this study demonstrates the correlation of community-based social distancing with $R_{t}$ using a measurable parameter. The evaluation of Google mobility scores alone as an index of social distancing is the main limitation of this study. However, the data obtained will form the basis for future studies. Interventions for reducing community-based social distancing significantly decreased the $R_{t}$ of COVID-19 as a result of decreasing human mobility and prevented many people from getting infected. Public health researchers should be more willing to evaluate digital data in future studies. Thus, determining the relationship of mobility data with other infectious diseases in future research will provide further insights into whether digital data are effective for monitoring the response to an epidemic. Another important result of the study is that it shows health policy-makers that data on human mobility in the community obtained via mobile phones can be a guide for measures to be taken.

\section{CONFLICT OF INTEREST}

The authors have no conflicts of interest associated with the material presented in this paper.

\section{FUNDING}

None. 


\section{ACKNOWLEDGEMENTS}

None.

\section{AUTHOR CONTRIBUTIONS}

Conceptualization: HD, MEG. Data curation HD, MEG. Formal analysis: HD, MEG, SM. Funding acquisition: None. Methodology: HD, MEG, SM. Project administration: HD, MEG, SM. Visualization: HD, MEG. Writing - original draft: HD, MEG, SM. Writing - review \& editing: HD, MEG, SM.

\section{ORCID}

Hasan Durmuş https://orcid.org/0000-0001-5719-1475

Mehmet Enes Gökler https://orcid.org/0000-0002-1524-8565

Selma Metintaş https://orcid.org/0000-0002-5002-5041

\section{REFERENCES}

1. Liu SL, Saif L. Emerging viruses without borders: the Wuhan coronavirus. Viruses 2020;12(2):130.

2. Hui DS, I Azhar E, Madani TA, Ntoumi F, Kock R, Dar O, et al. The continuing 2019-nCoV epidemic threat of novel coronaviruses to global health - the latest 2019 novel coronavirus outbreak in Wuhan, China. Int J Infect Dis 2020;91:264-266.

3. Lu R, Zhao X, Li J, Niu P, Yang B, Wu H, et al. Genomic characterisation and epidemiology of 2019 novel coronavirus: implications for virus origins and receptor binding. Lancet 2020; 395(10224):565-574.

4. Gralinski LE, Menachery VD. Return of the coronavirus: 2019nCoV. Viruses 2020;12(2):135.

5. Wang C, Horby PW, Hayden FG, Gao GF. A novel coronavirus outbreak of global health concern. Lancet 2020;395(10223): 470-473.

6. Guo YR, Cao QD, Hong ZS, Tan YY, Chen SD, Jin HJ, et al. The origin, transmission and clinical therapies on coronavirus disease 2019 (COVID-19) outbreak - an update on the status. Mil Med Res 2020;7(1):11.

7. Zhou P, Yang XL, Wang XG, Hu B, Zhang L, Zhang W, et al. A pneumonia outbreak associated with a new coronavirus of probable bat origin. Nature 2020;579(7798):270-273.

8. World Health Organization. WHO Director-General's opening remarks at the media briefing on COVID-19 - 11 March 2020 [cited 2020 Aug 1]. Available from: https://www.who.int/di- rector-general/speeches/detail/who-director-general-s-opening-remarks-at-the-media-briefing-on-covid-19---11-march2020.

9. Parry J. China coronavirus: cases surge as official admits human to human transmission. BMJ 2020;368:m236.

10. Hartley DM, Perencevich EN. Public health interventions for COVID-19: emerging evidence and implications for an evolving public health crisis. JAMA 2020;323(19):1908-1909.

11. Pan A, Liu L, Wang C, Guo H, Hao X, Wang Q, et al. Association of public health interventions with the epidemiology of the COVID-19 outbreak in Wuhan, China. JAMA 2020;323(19): 1915-1923.

12. Ucar A, Arslan S, Ozdemir MY. Nowcasting and forecasting the spread of COVID-19 and healthcare demand in Turkey, a modelling study. medRxiv 2020. doi: https://doi.org/10.1101/2020 04.13.20063305

13. Şeker M, Özer A, Tosun Z, Korkut C, Doğrul M. COVID-19 pandemic assessment report (English version). Ankara: Turkish Academy of Sciences; 2020, p. 43-48.

14. Demirbilek Y, Pehlivantürk G, Özgüler ZÖ, Alp Meşe E. COVID19 outbreak control, example of ministry of health of Turkey. Turk J Med Sci 2020;50(SI-1):489-494.

15. van den Driessche $P$, Watmough J. Further notes on the basic reproduction number. In: Brauer $F$, van den Driessche $P, W u J$, editors. Mathematical epidemiology. Berlin: Springer; 2008, p. 159-178.

16. Wallinga J, Lipsitch M. How generation intervals shape the relationship between growth rates and reproductive numbers. Proc Biol Sci 2007;274(1609):599-604.

17. Vrugt MT, Bickmann J, Wittkowski R. Effects of social distancing and isolation on epidemic spreading: a dynamical density functional theory model. arXiv preprint 2020;arXiv:2003.13967.

18. Google. Community mobility reports: see how your community is moving around differently due to COVID-19 [cited 2020 Apr 1]. Available from: https://www.google.com/covid19/ mobility/.

19. Datareportal. Digital 2020: Turkey [cited 2020 Sep 29]. Available from: https://datareportal.com/reports/digital-2020-turkey.

20. Republic of Turkey Ministry. COVID-19 information page [cited 2020 Apr 18]. Available from: https://covid19.saglik.gov.tr/? Dil $=2$.

21. University of Melbourne. Coronavirus 10-day forecast [cited 2020 Oct 1]. Available from: https://covid19forecast.science. unimelb.edu.au/. 
22. Obadia T, Haneef R, Boëlle PY. The RO package: a toolbox to estimate reproduction numbers for epidemic outbreaks. BMC Med Inform Decis Mak 2012;12:147.

23. Cori A, Ferguson NM, Fraser C, Cauchemez S. A new framework and software to estimate time-varying reproduction numbers during epidemics. Am J Epidemiol 2013;178(9):1505-1512.

24. Li Q, Guan X, Wu P, Wang X, Zhou L, Tong Y, et al. Early transmission dynamics in Wuhan, China, of novel coronavirus-infected pneumonia. N Engl J Med 2020;382(13):1199-1207.

25. Nelson KE, Williams CM. Infectious disease epidemiology: theory and practice. Burlington: Jones \& Bartlett Publishers; 2014, p. 77-80.

26. Kouadio IK, Aljunid S, Kamigaki T, Hammad K, Oshitani H. Infectious diseases following natural disasters: prevention and control measures. Expert Rev Anti Infect Ther 2012;10(1):95104.

27. Lai CC, Shih TP, Ko WC, Tang HJ, Hsueh PR. Severe acute respiratory syndrome coronavirus 2 (SARS-CoV-2) and coronavirus disease-2019 (COVID-19): the epidemic and the challenges. Int J Antimicrob Agents 2020;55(3):105924.

28. Liu Y, Gayle AA, Wilder-Smith A, Rocklöv J. The reproductive number of COVID-19 is higher compared to SARS coronavirus. J Travel Med 2020;27(2):taaa021.

29. Wilder-Smith A, Freedman DO. Isolation, quarantine, social distancing and community containment: pivotal role for oldstyle public health measures in the novel coronavirus (2019nCoV) outbreak. J Travel Med 2020;27(2):taaa020.

30. Rothe C, Schunk M, Sothmann P, Bretzel G, Froeschl G, Wallrauch C, et al. Transmission of 2019-nCoV infection from an asymptomatic contact in Germany. N Engl J Med 2020;382(10): 970-971.

31. Novel Coronavirus Pneumonia Emergency Response Epidemiology Team. The epidemiological characteristics of an out- break of 2019 novel coronavirus diseases (COVID-19) —China, 2020. China CDC Wkly 2020;2(8):113-122.

32. Ryu S, Ali ST, Jang C, Kim B, Cowling BJ. Effect of nonpharmaceutical interventions on transmission of severe acute respiratory syndrome coronavirus 2, South Korea, 2020. Emerg Infect Dis 2020;26(10):2406-2410.

33. Ryu S, Noh E, Ali ST, Kim D, Lau EH, Cowling BJ. Epidemiology and control of two epidemic waves of SARS-CoV-2 in South Korea. SSRN 2020. doi: http://dx.doi.org/10.2139/ssrn.3687061.

34. Chinazzi M, Davis JT, Ajelli M, Gioannini C, Litvinova M, Merler $S$, et al. The effect of travel restrictions on the spread of the 2019 novel coronavirus (COVID-19) outbreak. Science 2020; 368(6489):395-400.

35. Anderson RM, Heesterbeek H, Klinkenberg D, Hollingsworth TD. How will country-based mitigation measures influence the course of the COVID-19 epidemic? Lancet 2020;395(10228): 931-934.

36. Cowling BJ, Ali ST, Ng TW, Tsang TK, Li JC, Fong MW, et al. Impact assessment of non-pharmaceutical interventions against coronavirus disease 2019 and influenza in Hong Kong: an observational study. Lancet Public Health 2020;5(5):e279-e288.

37. Bayham J, Fenichel EP. Impact of school closures for COVID-19 on the US health-care workforce and net mortality: a modelling study. Lancet Public Health 2020;5(5):e271-e278.

38. Cheng VC, Wong SC, Chuang VW, So SY, Chen JH, Sridhar S, et al. The role of community-wide wearing of face mask for control of coronavirus disease 2019 (COVID-19) epidemic due to SARS-CoV-2. J Infect 2020;81(1):107-114.

39. Eikenberry SE, Mancuso M, Iboi E, Phan T, Eikenberry K, Kuang $Y$, et al. To mask or not to mask: modeling the potential for face mask use by the general public to curtail the COVID-19 pandemic. Infect Dis Model 2020;5:293-308. 